\title{
Consent: the patients' view — a summary of findings from a study of patients' perceptions of their consent to dental care
}

\author{
J. King,
}

\begin{abstract}
Aim A study was carried out which aimed to investigate peoples' perceptions of how their consent was given for dental treatment. Method A structured questionnaire was completed by 50 patients receiving treatment in the British NHS and 12 of them completed an in-depth recorded interview. The data was analysed using a combination of quantitative and qualitative methods.

Results The findings showed that $80 \%$ of patients had not been given any written treatment plan (FP17DC). $79 \%$ of patients mistakenly thought that the form signed requesting NHS treatment (FP17) was a consent form. When options were offered patients were more likely to consider that they were involved in the consenting process. However consent is still often implied rather than explicit. There was a range of experience reported by patients from those who felt that the dentist made the treatment decisions to those who felt that decisions had been made collaboratively. Although some patients were happy with the way their consent was obtained examples were also given of lack of information, confusion and even of deceit.

Conclusions There is an urgent need to clarify the status of NHS documentation regarding consent and a general need for awareness to be raised in the dental profession about the importance of obtaining consent which is freely given based on appropriate information which has been adequately understood.
\end{abstract}

$\mathrm{R}$ ecently a number of high profile cases reported in the media Rave drawn attention to patients' concerns about consent to treatment. ${ }^{1}$ Rising levels of litigation and the new European Human Rights legislation will increasingly demand a response from those who provide healthcare. ${ }^{2}$ The law relating to consent in this country remains in the professional domain, judged by what a responsible body of medical opinion would tell people about their treatment. This is in contrast to some parts of the world, for example in states in North America and Australia, where the law has adopted a more patient centred approach, the standard of disclosure being not what a doctor would tell a patient but rather what a reasonable person would want to know. ${ }^{3}$ This is an important

${ }^{1}$ Lecturer in Ethics and Law Applied to Dentistry, Department of Human Science and Medical Ethics and Dental School, St Bartholomews and the Royal London School of Medicine and Dentistry, Queen Mary and Westfield College, Turner Street, London E $12 \mathrm{AD}$

${ }^{*}$ Correspondence to: Jenny King

email:jenny.king@mds.qmw.ac.uk

REFEREED PAPER

Received 30.08.00; Accepted 07.12.00

(c) British Dental Journal 2001; 191: 36-40 moral shift towards a fuller recognition of patient autonomy in medical decision making and consenting to care.

Theoretical principles suggest that when a person is legally competent their consent to treatment is valid when it is based on information, understanding and non-coercion. ${ }^{4}$ Before starting any treatment a person should be informed about what is wrong, and about possible treatment options, including no treatment, and what each entails, and a consideration of the risks and benefits. ${ }^{5}$ Professional guidelines from the General Dental Council reiterate these principles in relation to dentistry. ${ }^{6}$

However in practice there is still considerable confusion about consent and much remains implied rather than being made explicit. ${ }^{7}$ For example our previous research has found that the form in use in General Dental Services which requires a patient's signature is mistakenly regarded as a consent form by two thirds of dental practitioners. ${ }^{8}$ Furthermore written treatment plans are not always given to patients although they are a stipulated requirement in NHS regulations, other than for very routine care. ${ }^{9}$ It is these findings which have prompted this investigation into patients' perceptions of consent to dental treatment.

\section{Study methods}

A small study was carried out based in the dental examination centres of the NHS Dental Practice Board in Sussex, London, Birmingham and Leeds. The aim of the study was to investigate to what extent users of General Dental Services feel informed about their dental treatment and the way in which their consent is obtained. Local ethics committee approval was obtained to carry out the study.

The participants were volunteers who gave their consent to take part and all information was collected anonymously. No link was made with the dentist providing clinical care. Fifty competent adults receiving dental treatment within General Dental Services completed a short fixed choice questionnaire and 12 of them completed a longer open ended interview which was tape recorded and then transcribed.

The questions focused on the information that was given, how that information was understood and how freely consent was given. These three theoretical components of consent formed the framework for coding the interview text. The analysis of the data included a combination of both quantitative and qualitative methodology. Using complementary approaches in this way is one well recognised means of validating the research findings. The questionnaires were processed using a quantitative computer program (SPSS) and the findings are reported in tables. The text of the interviews was systematically coded into different categories and retrieved using a program for managing qualitative data, (QSRNUD $\left.{ }^{*} I S T 4\right)$. Patients own comments are reported verbatim to illustrate the range of views expressed about the issues that were raised. Pseudonyms are used in the reporting. 


\section{RESEARCH ethics \& law}

Table I Information received by respondents

\begin{tabular}{lll}
\hline $\mathrm{N}=50$ & Yes (\%) $\quad$ No (\%) \\
\hline
\end{tabular}

\section{Information about:}

- The problem

- Procedure

- Risks and benefits

- Options

- Cost

- Time

$\begin{array}{ll}90 & 10 \\ 84 & 16 \\ 74 & 26 \\ 66 & 34 \\ 66 & 34 \\ 60 & 40\end{array}$

Table 2 Use of NHS forms

\begin{tabular}{lcc}
\hline $\mathrm{N}=50$ & Yes (\%) & No (\%) \\
\hline Received a written treatment plan & 20 & 80 \\
Regarded FPI7 as a consent form & 79 & 21 \\
\hline
\end{tabular}

Table 3 The relationship between options and joint decision making

\begin{tabular}{lccc}
\hline$N=49$ & Joint decision & Dentist decision & Significance \\
\hline Options & 29 & 3 & $P>.001$ \\
No options & 7 & 10 & \\
\hline
\end{tabular}

\section{Findings from the study}

\section{Responses to the questionnaire}

The findings from the questionnaire study suggest that $90 \%$ of the respondents had some information about their dental problems; $82 \%$ had the procedure explained, $74 \%$ indicated that had been told about risks and benefits, $66 \%$ about options, $66 \%$ about costs, and $60 \%$ about the time their treatment would take. But although many patients reported positively there was still a significant proportion of patients embarking on treatment with no basic information about what their treatment would entail (18\%), its risks and benefits $(26 \%)$ or any alternative treatments $(34 \%)$, any costs ( $34 \%)$ and the time it would take $(40 \%)$ (Table 1$)$.

Relatively few, $20 \%$ of respondents, had received any written treatment plan. Furthermore most people thought that the form that they had signed requesting NHS treatment was also a consent form, $79 \%$ (Table 2).

Many people, $74 \%$, considered that they had been included in making decisions, but $26 \%$ of the respondents felt that it was the dentist alone who had decided. Further analysis of the findings suggest that a key factor is whether or not people have received any information about treatment options; 29 of the 36 people making joint decisions had been told about treatment alternatives, compared with 3 of the 13 people who felt that it was the dentist who made the decisions. This difference is statistically significant. $(P>.001)$ (Table 3$)$.

\section{Responses to the interview : the basic principles of consent Information}

Consent must be based on appropriate information about a person's dental problem and its treatment. Some people who took part in the interview had regular dental treatment. Others had gone to the dentist because they had trouble, for instance two loose front teeth, a request for a denture for a son's wedding, severe toothache. People were often already well aware of their own dental situation. 'I asked what could be done about my shaky teeth and after the examination they decided dentures and suggested it would really be the best thing to do, because of course I realised that.' (Pete) Dentists provided further information about dental problems. 'He did say that I could either have them all pulled out or try and save some of them, which is what we are trying to do.'(Linda)
People described different ways in which they received information. 'It was all verbal information, it was the dentist explaining what was needed next and in very simple terms really, in this particular case it was a replacement crown so he was saying you need one because and explained why.'(Christopher) Mostly information was given verbally by the dentist but literature was sometimes available and also posters and videos. The dental nurse was sometimes able to augment information given by the dentist. One woman who was having a crown made described how the latest technology in oral video cameras showed her back teeth on a screen.

Although some people felt they had received good information others felt ill informed about their treatment. 'I was very naive about it, what the terms were even. I was not even sure what I had fitted. There wasn't much discussion ... there were definitely no leaflets or plan or anything like that.' (Carol) Treatment was not always well explained or options discussed. 'I didn't know anything about it. It would be nice to know what I was actually having done or whether there were alternative treatments.'(John)

\section{Understanding}

For consent to be valid people must not only have the information they must also understand it. Some people felt that they understood reasonably well. 'It was all explained to me and I did take it in.' (Stella) 'He told me what he was going to do so I had a fair idea. I wasn't put out by it.' (Pete) When people have had previous experience of treatment, for example fillings or cleaning, they feel that they do already understand what to expect. 'I've had it done so many times it was more or less accepted that I knew.' (Muriel) However a new treatment, such as a crown, might require further explanation from the dentist. 'I felt that it is the routine stuff that seems to have less consent, and the more complex stuff consent is properly sought or at least it is explained.' (Christopher) The chance to ask questions, having the chance to think about it before deciding, the approachability of the dentist and a confident relationship were all mentioned as helping understanding. 'I have tended to find the dentists I have had of recent years have been quite friendly and been quite willing to talk within a time slot, if you need them to, despite their being busy, so no I have been quite happy.' (Christopher)

However explanations were not always given, assumptions were made that people understood when they did not. 'I just think that he presumed that I would know.' (Jan) Several people mentioned that when dentists were rushed there was not always time for explanations or questions 'It is very difficult to find a dentist who will treat you properly, who will explain to you, they are always in a rush.' (Ludmilla) 'I think they seem under pressure. Talking something over like that takes a lot of time, and time is money. It's a conveyor belt, in and out as quickly as possible.' (John) 'I think the big problem is you don't quite know what they are doing most of the time ... you are trusting an awful lot of things.' (Christopher)

\section{Non-coercion}

Once people have the appropriate information and understanding then consent must be freely given and not manipulated. In some cases decision making was described as a shared activity where there was no coercion, 'I was quite happy with the way it was done. He didn't force me to have a filling I didn't want done. No pressure at all.' (Jan) However the interviews described how patients may simply be told rather than asked about what is going to be done. 'They just told me what needed doing and I went along with the flow.' (John) In some instances people defer to dental expertise and agree with the dentist. 'I suppose if you want it doing you have got to consent to it, there are no two ways about it really, you go along with the dentist, he is the professional and if you want it done you have to agree with it.' (Linda) At times it was the problem itself that seemed to dictate what should happen. 'No I didn't need 
persuasion. I had the pain. The pain was enough persuasion for me. (Samuel)

\section{Consent}

Some people said how they had felt free to give their consent and had felt in control of their situation, 'Yes he told me what he was going to do, it was up to me to have it done' (Linda) In some cases verbal agreement to proceed was given, 'He said, 'Are you happy with that?' 'I said yes.' (Stella) But consent was often assumed because appointments were made and kept. 'I felt that by agreeing to the next appointment, pretty much that was consent.' (Christopher) Others felt that it was the dentist who remained in control. 'The only control I had was making the appointment so once I got in there it was his control totally.' (Carol) Written consent was not usual, and this remains an area of considerable confusion which will be discussed later.

\section{Responses to the interview : emerging themes}

Four themes which emerged from the analysis of the interviews with patients will be described: the experience of interactive dialogue; the difference that offering choices makes; the value of written documentation; and past experiences and changes.

\section{The experience of interactive dialogue}

Examples were given of the dialogue which takes place between dentists and patients in reaching decisions. Jo had toothache and wanted all his teeth taken out, but Jo's dentist encouraged him to keep his sound teeth.

'When I first went to see him I was in agony. I asked him to take the whole lot out. And he explained to me. He said we will save them for two reasons because if you have some dentures put in it is better to have some of your own teeth there to support them. He also said some of my own teeth there was nothing wrong with them so why take them out.' (Jo)

Samuel described how he and his dentist had taken the time to listen to each other and had negotiated treatment together.

'He did it quite clearly and quite plainly and slowly, no rush, he took his time, and said what he had to say. I listened, then I gave him my opinion of what I thought and we decided together.' (Samuel)

When there is a cost involved it may influence the interaction and Muriel thought that her dentist had asked her whether she wanted her teeth cleaned because she would have to pay for it. 'I was asked if I wanted the clean and polish. I suppose its because I had to pay for that.' (Muriel) Carol thought that her dentist might have given her better information if she had been a private patient. 'Maybe if I was a private patient he might have discussed it.' (Carol)

People may feel that they have more control of some aspects of their dental care than others, for example they were free to make and attend appointments, whilst the dentist had control of the treatment decisions. Asking questions was described by Pete as one way of gaining more control of his situation.

'When I went in to have the treatment done, at that stage one isn't controlling the thing because you know one is a patient and to some extent at the mercy of the practitioner, but on the other hand one can always ask questions, questions are pretty routine really, about how long, what should I take if it doesn't stop bleeding, and that sort of thing, I suppose that gives one some control.' (Pete)

Stella on the other hand felt more in control and only agreed to treatment when she felt that things had been explained to her.

'Consent is down to you at the end of the day isn't it. You are going to have the treatment or not. If I am happy with the way things have been explained then I will go ahead.' (Stella)

The difference that taking time and offering choices makes People described the difference that being offered explanations about the different treatment options had made. Stuart, a regular dental patient, appreciated the explanations that a new dentist had offered. Having choices made him feel much more involved in his own dental care.

'It helps me a lot because previously I have been for dental treatment and I have had it and it has been fine, but I just don't know what they have done ... Recently I have been given a choice of different filling etc. and explained what the differences is between them. When I meet Mr W I feel as though he is explaining, I know what is being done and I feel as though I am part of the treatment, rather than just the person in the chair.' (Stuart)

Stella was grateful that having been offered different options it was suggested that she should go away and think about it before making any final decisions.

'They said if you want to go away and think about it and let us know. I had that option which I thought was good and helpful. I always feel uneasy at the dentist. I could go away and think about it and talk to them again when I wanted it done.' (Stella)

\section{The potential for written documentation}

Some people had received written treatment plans and they described how these had been useful to explain the treatment, its cost and how long it might take. It provided a written record for people to keep.

'He always explains what needs doing and it's written down all this, he crosses out what doesn't want doing, and he tells me what the approximate cost will be ... I find that very useful because I know exactly how much it is going to be and what needs to be done and have a good idea how many treatments I need ... it allows you to plan other things I know when I have finished, I am done on this visit, I have finished this particular treatment, it's favourable in that way' (Stuart)

'It was all computerised, a big sheet, it was explaining costs. I've got that at home still.' (Stella)

People expressed some confusion about the form that they had signed at the dentist. They would have liked more explanation about it. 'I had to fill in a form. I don't know what form it was. I think it was a registration form.' (Jo) 'The forms that you are given could have been explained to a bit better.' (John)

Carol explained how better information and written authorisation would have helped her. She would have liked to have understood more about her treatment and given her written consent before proceeding.

'There was no discussion and it was just I am going to do this or he may have said you need this... I just assumed he had done what he had to do and that was it. There was no authorisation ... I don't think I signed a form to authorise. Maybe I would have signed a form for the NHS.' ... 'I think you should sign something... It should be a lot more clear than it is at the moment, it should be more explained.' (Carol)

\section{Past experiences and changes}

Several of the respondents recounted stories of their previous experience with dentists.

Ludmilla had changed her dentist because she had an unsuccessful restoration and eventually the tooth had to be taken out at a dental hospital. She felt that her dentist had not explained things properly to her, so much so that she had thought of taking legal action.

'She never told me this information, and this is really very bad. I was thinking to go to the solicitor to take legal action because I suffered a lot from the teeth. I don't know what will happen in future, but in the first meeting (with a new dentist) he explained to me about the teeth and I hope this time I will be happy.' (Ludmilla)

One man described how in the past he had been lied to when the dentist had explained that he would make a crown costing one hundred pounds. In the event he made two crowns without informing the patient and charged him twice as much. He did not return to that dentist.

Stuart recalled how in the past dentists were regarded as the 


\section{RESEARCH ethics \& law}

experts who could not be questioned, but that now dentists were less arrogant and more approachable.

'You just assume that if you don't want toothache you have got to go to the dentist regularly, and I have just gone along with this. But in latter years I have found myself reading and asking more questions. Perhaps it's because you feel they should tell you more as opposed to when as a youngster you think dentists and doctors are God and you don't question these people really. They are the experts, they do what they want. But its not like that now.' (Stuart)

Carol remembered her own childhood and how the dentist had not communicated with her. She hoped that things would be better for her children and that they would be more involved in their own healthcare.

'I have always been taken to the dentist by my parents as a child and they sat in the waiting room and I went in. That was it. There was no communication. Maybe the dentist used to speak to my parents about it. But I would like my children to be a bit wiser about what is going on, to have better control on what is happening with their health.' (Carol)

\section{Discussion}

This study has investigated how patients give dentists their consent to be treated. The combined methods of qualitative and quantitative analysis that have been used demonstrate how each method is appropriate for different kinds of information. For example the quantitative analysis of a fixed choice questionnaire was used to investigate the proportion of people who regard the FP17 as a consent form. On the other hand the qualitative analysis of the interviews explored in greater depth people's own perceptions of their consent to dental care. Qualitative analysis has not been widely used in dental research but its value in medical research is becoming increasingly recognised as, 'Reaching the parts that other research cannot reach. 10

Ozar and Sokol in their book, Dental Ethics at Chairside, ${ }^{11}$ describe an interactive model of dentistry where treatment is mutually agreed and consented to by dentists and patients together following an exchange of information. They suggest that morally this shared decision making is the ideal which should be worked towards in clinical relationships. This is in contrast to other theoretical models of dentistry where decisions are patient led, dentist led, or commercially driven. In the reality of the dental clinic all of these models are likely to operate to a greater or lesser extent. This study has found evidence of both paternalistic decision making by the dentist and instances where the person receiving care feels in control of their situation. Dentistry would appear to be moving away from old paternalistic practices to more collaborative approaches. The findings suggest that in order for decision making to be interactive information must first be given by the dentist. When the dentist offers choices the consultation is opened up to a greater sharing of responsibility between dentists and patients as they reach an agreement about the final treatment plan that is consented to.

Reaching a mutual understanding is likely to require time. However NHS dental treatment may seem to be very rushed with little time made available for explanations, questions or discussion. However some dentists clearly did take the time to talk to their patients and this was something that was appreciated. The rigid NHS fee structure does not specifically allow a fee for the time that is needed to communicate well with patients, whether this is for health advice or providing information. Another factor against understanding is the paternalistic attitude of dentists which may be coupled with a deference towards expert knowledge and opinion shown by patients. A patient is simply told what is going to be done and agrees with the expert without question. This very unequal situation leaves little room for weighing up the advantages and disadvantages of any one treatment for either the dentist or the patient. The cost of dental treatment is significantly greater than it has been in the past and this means that dentists must now explain these costs in more detail. This may well have the effect of making dentists more accountable to their patients. This is likely to be even more so for private patients.

Consent is much more than a person simply agreeing with the dentist or signing a form; it is a process with definite stages which depends on a person having and understanding the appropriate information before treatment can be agreed and finally consented to. What is clear from this study is that for the majority of patients dental care proceeds without anything in writing. However when written information was given to patients, either as a duplicated treatment plan (FP17DC) or a computerised record, it was described as useful. Consent to treatment is usually assumed or given verbally, although many dentists and patients mistakenly regard the FP17 form as a consent form. This confusion means that dental treatment may often be carried out under a misapprehension. Changes in patient expectations about their rights to consent based on information and choice, as well as the increasing threat of litigation, suggest that clarification of the status of this form is urgently needed. A written treatment plan and a more explicit consent form would not of themselves raise standards of consent in dentistry. Forms can never take the place of the necessary dialogue between dentists and patients. However by providing a written record they would act as a useful focus for information and consent and avoid some of the confusion that currently exists.

People are now more likely to have explanations and be offered choices when they go to the dentist than in the past, and it is now easier for people to ask questions. This means that patients feel more able to be involved in their dental care. However examples of patients being told rather than asked about their care remain. There is a potential for the next generation of dental patients to receive more information and to give their consent to be treated much more explicitly.

Better information and more explicit consent within General Dental Services would be supported by making the existing documentation more explicit and more user friendly. Other parts of the health services are developing guidelines which include written consent. The impetus for change should come from the dental profession because it is recognised as being morally right rather than being forced to change by public pressure, or the threat of litigation.

\section{Conclusions and recommendations}

From this study it must be concluded that there is a wide variation in consenting practice, ranging from people who feel that they have given their consent quite freely to those who feel that it is the dentist who takes control. People even described times when they had been deceived by the dentist about their treatment.

Recommendations from this study for raising the standards of consent in dentistry are therefore to:

- Increase undergraduate and postgraduate training of dentists about consent, and the communication skills required.

- Raise public awareness by focusing more explicitly on consent

- Place more emphasis on the educative role of dentists and recognition of this in NHS fee structures

- Seek ways of clarifying existing NHS documentation (i.e. FP17DC and FP17)

Dentistry must continue to respond to changes in public expectations and seek to make interactive decision making a greater reality within the clinical consultation. Without proper consent dental treatment is in danger of becoming mistreatment. Moral and legal considerations, as well as the demands of good practice, call for consent to be taken very seriously by dentists and patients 
alike. This is to respect the essential human capacity for choice and self determination.

The author gratefully acknowledges funding received from the Kings Fund, although the views expressed are those of the author. Thanks are also due to the Dental Practice Board and all the people who took part in the questionnaires and interviews.

1 Doyle C. Question marks over consent. Daily Telegraph Feb 22, 2000.

2 Grubb A. In the preface to vol 50 Butterworth Medical Legal Reports Butterworths, 1999.

3 Brazier M. Medicine patients and the law. London: Penguin, 1993, p80-81.

4 Faden R, Beauchamp T. A history and theory of informed consent. Oxford: Oxford University Press, 1986.
5 General Medical Council. Duties of a doctor — seeking patients' consent www.gmc-uk.org

6 General Dental Council Maintaining Standards, 1997.

7 King J, Hillier S, Doyal L. Consent in dental care. London: Kings Fund, 2000 .

8 King J. Confusion about consent in Dental Profile. Dental Practice Board, May 2000 p 6-7

9 The National Health Service (General Dental Services) Regulations 1992 p2414-2415.

10 Pope C, Mays N. Reaching the parts other methods cannot reach: an introduction to qualitative methods in health and health care research. $\mathrm{Br}$ Med J 1995; 313: 42-45.

11 Ozar D, Sokol D. Dental ethics at chairside. London: Mosby, 1994 p38-50. 